DE

M E D I C I N A

T R O P I C A L

$\mathrm{DE}$

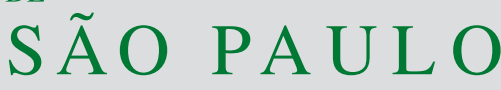

JOURNAL OF THE SÃO PAULO INSTITUTE OF TROPICAL MEDICINE

(1) Universidade do Sul de Santa Catarina, Faculdade de Medicina, Departamento de Ciências Biológicas e da Saúde e de Ciências Sociais Aplicadas, Disciplina de Doenças Infecciosas, Palhoça, Santa Catarina, Brazil

(2)Universidade Federal de São Paulo, Disciplina de Infectologia, São Paulo, São Paulo, Brazil

(3)Universidade de São Paulo, Faculdade de Medicina, Divisão de Gastroenterologia e Hepatologia, São Paulo, São Paulo, Brazil

(4)Universidade Federal do Estado do Rio de Janeiro, Departamento de Clinica Médica, Disciplina de Gastroenterologia, Rio de Janeiro, Rio de Janeiro, Brazil

(5) Universidade Federal do Espírito Santo, Serviço de Infectologia, Vitória, Espírito Santo, Brazil

(6) Universidade de São Paulo, Faculdade de Medicina de Ribeirão Preto, Divisão de Gastroenterologia, Ribeirão Preto, São Paulo, Brazil

(7)Instituto de Infectologia Emilio Ribas, São Paulo, São Paulo, Brazil

(8) Universidade de São Paulo, Faculdade de Medicina, Departamento de Doenças Infecciosas e Parasitárias, São Paulo, São Paulo, Brazil

(9)Secretaria Estadual de Saúde, Unidade Mista de Saúde - Unimista 508/509, Brasília, Distrito Federal, Brazil

(10) Universidade de São Paulo, Instituto de Medicina Tropical de São Paulo, LIM-52, Laboratório de Virologia, São Paulo, São Paulo, Brazil

Correspondence to: Aline Vitali Grando Universidade do Sul de Santa Catarina, Faculdade de Medicina, Departamento de Ciências Biológicas e da Saúde e de Ciências Sociais Aplicadas, Disciplina de Doenças Infecciosas, Av. da Pedra Branca, 25, Pedra Branca, CEP 88137-270, Palhoça, SC, Brazil Tel: $+55483279-1152$

Fax: $+55483279-1000$

E-mail: aline.grando@unisul.br, vitali.aline@gmail.com

Received: 29 January 2017

Accepted: 13 July 2017

\section{Peginterferon still has a place in the treatment of hepatitis C caused by genotype 3 virus}

\author{
Aline Vitali Grando', Paulo Roberto Abrão Ferreira², Mário Guimarães \\ Pessôa $^{3}$, Daniel Ferraz de Campos Mazo $^{3}$, Carlos Eduardo Brandão-Mello ${ }^{4}$, \\ Tânia Reuter ${ }^{5}$, Ana de Lourdes Candolo Martinellib, Mário Peribanez \\ Gonzalez ${ }^{7}$, Ana Catharina Seixas-Santos Nastri ${ }^{8}$, Aléia Faustina Campos ${ }^{8}$, \\ Max Igor Banks Ferreira Lopes ${ }^{8}$, José David Urbaez Brito ${ }^{9}$, Maria Cássia \\ Mendes-Corrêa ${ }^{8,10}$
}

\section{ABSTRACT}

Despite recent advances in therapy for chronic hepatitis $\mathrm{C}(\mathrm{CHC})$, the disease caused by genotype 3 virus (GEN3) is still considered a treatment challenge in certain patient subgroups. The aim of this retrospective study was to evaluate the effectiveness and safety of the peginterferon (Peg-IFN) and ribavirin (RBV) combination treatment for GEN3/CHC patients, and to evaluate sustained virological response (SVR) indicators and early treatment interruption due to serious adverse events (SAE). This was a retrospective observational study of GEN3/CHC patients, co-infected or not by HIV and treated with Peg-IFN/RBV in nine Brazilian healthcare centers. The study sample included 184 GEN3/CHC patients; $70(38 \%)$ were co-infected with HIV. The overall SVR rate was 57.1\% (95\% CI 50-64). Among coinfected and mono-infected patients, the SVR rate was 51.4\% (36/70) and 60.5\% (69/114), respectively $(\mathrm{p}=0.241)$. Thirty-four $(18.5 \%)$ patients experienced SAE and interrupted treatment. SVR was negatively associated with the use of Peg-IFN alpha 2b (PR 0.75; 95\% CI 0.58-0.99; $\mathrm{p}=0.045$ ) and to early treatment interruption due to SAE (PR 0.36; 95\% CI $0.20-0.68 ; \mathrm{p}=0.001)$. Early treatment interruption due to SAE was associated with age (PR 1.06; 95\% CI 1.02-1.10; $\mathrm{p}<0.001)$ and occurrence of liver cirrhosis (PR 2.06; 95\% CI 1.11$3.83 ; \mathrm{p}=0.022$ ). In conclusion, Peg-IFN/RBV might represent an adequate treatment option, mainly in young patients without advanced liver disease or when the use of direct-action drugs is limited to specific patient groups.

KEYWORDS: Hepatitis C. Chronic hepatitis C. Coinfection HCV-HIV. Interferons. Ribavirin. HCV genotypes.

\section{INTRODUCTION}

Hepatitis C virus (HCV) infects 185 million people worldwide' ${ }^{1}$ The HCV genotype 3 (GEN3) represents the second most common genotype, corresponding to $30 \%$ of infection cases ${ }^{1}$. The prevalence of patients with GEN3 in Brazil ${ }^{2}$ and in tropical Latin America ${ }^{1}$ is among the highest in the world. This genotype is also the most frequent among injectable drug users and often occurs in individuals who are co-infected by $\mathrm{HIV}^{3}$. Different studies suggest that GEN3 is associated with the more aggressive forms of hepatic disease, including hepatic cirrhosis and hepatocellular carcinoma ${ }^{4}$.

The use of pegylated interferon (Peg-IFN) in combination with ribavirin (RBV) 
was until recently the therapy of choice for patients with chronic hepatitis $\mathrm{C}(\mathrm{CHC})^{5}$. However, the development of direct-action antiviral (DAA) agents improved the rates of success in the treatment of $\mathrm{HCV}$, especially $\mathrm{HCV}$ genotype 1 , both in mono- and co-infected patients ${ }^{5-7}$. In different regions of the world, DAAs have also become the main line of action against GEN3/CHC ${ }^{8}$. However, cirrhotic patients infected with GEN3 do not respond as well to this new drug generation ${ }^{4,5,7,9}$. Moreover, the universal use of these drugs is limited by their high $\operatorname{cost}^{8}$.

The analysis of real-life patient cohorts treated with Peg-IFN/RBV may yield important information for future decision making based on the effectiveness and safety of new drugs, if compared with the classic standard therapy. Knowledge of patient groups at higher probability for therapeutic success and at lower risk of interruption due to serious adverse events (SAE) may support the inclusion of classic therapy as a viable alternative in specific contexts.

The present study aimed at evaluating the effectiveness and safety of the Peg-IFN/RBV combination treatment for patients with GEN3/CHC, with or without HIV co-infection, in a real-life context. It has also assessed what factors may better predict a SVR and the early treatment interruption due to SAE.

\section{MATERIAL AND METHODS}

\section{Study design and patient selection}

We conducted an observational, retrospective and multicentric study with non-probability sampling that has investigated the disease outcome in patients infected by HCV/GEN3, with or without HIV co-infection, and treated with Peg-IFN/RBV in a real-life context between January 2005 and October 2010, in nine secondary or tertiary healthcare reference centers in Brazil, as follows: Departamento de Doenças Infecciosas e Parasitárias da Faculdade de Medicina da Universidade de São Paulo (USP), São Paulo; Departamento de Gastroenterologia e Hepatologia da Faculdade de Medicina da Universidade de São Paulo (USP), São Paulo; Universidade Federal de São Paulo (UNIFESP), São Paulo; Centro de Referência e Tratamento DST-AIDS de São Paulo; Universidade Federal do Estado do Rio de Janeiro (UNIRIO), Rio de Janeiro; Universidade Federal do Espírito Santo (UFES), Vitória; Faculdade de Medicina da Universidade de São Paulo, Ribeirão Preto; Instituto de Infectologia Emilio Ribas, São Paulo; Unidade Mista de Saúde - Unimista, Brasília.

All patients admitted in these centers were included and received a minimum of one dose of Peg-IFN during the treatment regimen of 24 to 48 weeks. Treatment regimens were conducted in accordance with the guidelines defined by the Brazilian Health Ministry, following international recommendations.

Patients were included when they met the following criteria: being 18 years old or older; having infection by HCV/GEN3 confirmed through a molecular biology test for the detection or quantification of viral RNA (HCV RNA); having taken at least one dose of Peg-IFN, in any form available, including Peg-IFN alpha 2a (Pesagys, Roche) or Peg-IFN alpha $2 b$ (Pegintron, MSD), in combination with RBV. The HIV infection diagnosis followed the criteria defined by the Brazilian Health Ministry ${ }^{10}$. Patients with hepatitis B virus co-infection or who had previously used Peg-IFN were excluded from the study. The study was approved by the Research Ethics Committee on Humans of all centers involved in the research and, given its retrospective nature, we were not able to collect informed consent from all study participants. Data were obtained by assessing the patients' records as authorized by the Ethics Committee for Analysis of Research Projects from each of the involved medical centers.

\section{Evaluation of effectiveness}

The sustained virologic response (SVR) provided a measure of effectiveness. A patient was considered to have SVR when HCV RNA could not be detected $(<50 \mathrm{UI} / \mathrm{mL})$ by the ultrasensitive PCR method ${ }^{11}, 24$ weeks after the end of treatment with Peg-IFN/RBV. All patients admitted in these centers were included and received a minimum of one dose of Peg-IFN during the treatment regimen of 24 to 48 weeks.

Among patients who did not experience SVR, other types of response were evaluated, depending on viral kinetics, defined as: 1) viral relapse (HCV RNA was undetectable at the end of treatment, but detectable at the 24-week follow-up); 2) viral escape (undetectable HCV RNA during treatment followed by appearance of HCV RNA, despite continued treatment); 3) no response (HCV RNA level less than $2 \log _{10}$ decline between baseline and week 12 or HCV RNA detectable at the end of treatment).

\section{Safety evaluation}

We evaluated and described the causes for early treatment interruption associated with SAE due to Peg-IFN/ RBV. The causes included hematological, cutaneous, and psychiatric alterations, infections, hepatic decompensation, drug intolerance, drug unavailability, decompensation of other comorbidities. SAE included all events that resulted in early treatment interruption. Moreover, treatment 
intolerance was defined as the presence of non-specific symptoms such as inappetence, irritability, weight lossand a general sensation of discomfort that led to treatment interruption.

Other forms of interruption were also evaluated such as non-adhesion or treatment abandonment.

\section{Analyzed variables}

The variables selected for analysis were grouped into several categories: 1) demographic variables and status of the metabolic syndrome; 2) variables related to $\mathrm{HCV}$ infection (last registered alanine aminotransferase test results (ALT) prior to treatment; pattern of liver fibrosis and the occurrence of hepatic steatosis); 3 ) variables related to $\mathrm{HCV}$ treatment (history of treatment with conventional interferon, type of Peg-IFN used, duration and dose of RBV use, HCV RNA detection during treatment at weeks 12 and 24, and 24 after the beginning of treatment, occurrence and causes for early treatment interruption). Patients were considered to have metabolic syndrome if they met three out of five criteria defined by the National Cholesterol Education Program, Adult Treatment Panel III ${ }^{12,13}$, including: 1) serum triglycerides above $150 \mathrm{mg} / \mathrm{dL}$ or use of triglyceride-control medication; 2) serum HDL below $40 \mathrm{mg} / \mathrm{dL}$ for men or $50 \mathrm{mg} / \mathrm{dL}$ for women or use of medication for low HDL; 3) arterial pressure above $130 / 85 \mathrm{mmHg}$ or use of antihypertensive medication; 4) plasma glucose above $110 \mathrm{mg} / \mathrm{dL}$ or use of hypoglycemic medication; 5) body mass index above $28.8 \mathrm{~kg} / \mathrm{m}^{2}$ for men and women.

We defined the adequate RBV dose as the use of at least $800 \mathrm{mg} /$ day. Normal alanine aminotransferase (ALT) values were defined as $31 \mathrm{U} / \mathrm{L}$ for women and up to 41 $\mathrm{U} / \mathrm{L}$ for men.

\section{Data analysis}

Data were analyzed by the STATA software version 13.0 (StataCorp LP, College Station, Texas, USA). The descriptive analyses of demographic, clinical, and therapeutic characteristics of $\mathrm{CHC}$ patients were reported as frequencies for qualitative variables and as estimate measures of central tendency and dispersion for quantitative variables. Contingency tables were used for the analysis of differences between mono-infected (HCV) and co-infected (HCV/HIV) patient groups through the Chi-square test (or Fisher exact-test) and through the unpaired Student's t-test. Prevalence ratios (PRs) were estimated with their respective 95\% CI for the bivariate analysis of the relationship among several variables and the outcomes of interest: SVR and early treatment interruption due to SAE. A p-value below 0.05 was considered statistically significant.

Variables that, after bivariate analysis, experienced a p-value below 0.20 were selected for the multiple analysis using the Poisson regression with robust variance. However, we could not fit a multivariate model with statistical significance with the data obtained in this study.

\section{RESULTS}

The present study included 184 GEN3-infected individuals, among whom 114 (62\%) were mono-infected and $70(38 \%)$ were co-infected with HIV. Table 1 displays the main characteristics of the study population.

Table 1 - Clinical and treatment variables of mono-infected patients with HCV and co-infected patients with HCV/HIV

\begin{tabular}{|c|c|c|c|}
\hline Variable & Mono-infected & Co-infected & P-value \\
\hline Males, n/N (\%) & $62 / 114(54)$ & $49 / 70(70)$ & 0.036 \\
\hline Age, mean (SD) & $50.5(9.2)$ & $44.5(6.6)$ & $<0.001$ \\
\hline ALT 2x/UNL, n/N (\%) & $61 / 114(54)$ & $31 / 67(46)$ & 0.347 \\
\hline Cirrhosis $^{b}, \mathrm{n} / \mathrm{N}(\%)$ & $35 / 114(31)$ & $14 / 65(22)$ & 0.186 \\
\hline Inflammatory activity 3 and $4^{c}, n / N(\%)$ & $12 / 102(12)$ & $26 / 49$ (53) & $<0.001$ \\
\hline Liver steatosis, n/N (\%) & $57 / 99(58)$ & $27 / 49(55)$ & 0.775 \\
\hline Retreatment, n/N (\%) & $59 / 114(52)$ & $26 / 68(38)$ & 0.077 \\
\hline Current treatment, $\mathrm{n} / \mathrm{N}(\%)$ & & & 0.312 \\
\hline Peg-IFN 2a & $66 / 110(60)$ & $35 / 67$ (52) & \\
\hline Peg-IFN 2b & $44 / 110(40)$ & $32 / 67$ (48) & \\
\hline Adequate initial dose of Ribavirind, $n / N(\%)$ & $92 / 103(89)$ & $52 / 58(90)$ & 0.947 \\
\hline Adequate Ribavirin dose throughout the treatment, $\mathrm{n} / \mathrm{N}(\%)$ & $83 / 103(81)$ & $6 / 11(55)$ & $0.061^{*}$ \\
\hline
\end{tabular}

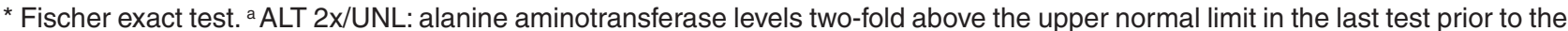
beginning of treatment. ${ }^{b}$ Liver biopsy with Metavir fibrosis stage F4 or clinical manifestations of hepatic cirrhosis. ${ }^{\mathrm{c}}$ Inflammatory hepatic activity determined by liver biopsy and Metavir score. ${ }^{d}$ At least $800 \mathrm{mg} /$ day 
Among the 184 included patients, 105 had SVR. Thus, the overall SVR rate was $57.1 \%$ (95\% CI 50-64). Among co-infected patients, the rate was $51.4 \%(36 / 70)$ and among mono-infected ones, it was 60.5\% (69/114) $(\mathrm{p}=0.241)$. Among patients with cirrhosis, SVR was observed in a total of 22 patients, and 18 out of $35(51.4 \%$; $95 \% \mathrm{CI}$ $34-68)$ were mono-infected and 4 out of $14(28.6 \%$; $95 \%$ CI 8.4-58.1; $\mathrm{p}=0.146)$ were co-infected. Nine patients $(5 \%)$ were considered non-responders to treatment, in 17 patients (9\%) the disease relapsed and $2(1 \%)$ presented viral escape.

To identify factors associated with SVR in patients with GEN3 CHC, we tested the relationship between this response and each study variable (Table 2). Bivariate analysis indicated that the use of Peg-IFN alpha $2 b$ (PR $0.75 ; 95 \%$ CI $0.58-0.99 ; \mathrm{p}=0.045$ ) and early treatment interruption due to SAE (PR 0.36; 95\% CI 0.20-0.68; $\mathrm{p}=0.001$ ) were both negatively associated with SVR.
The absence of liver cirrhosis was not significantly associated with SVR, although a tendency was observed. Among 49 patients with cirrhosis, 22 (44.9\%) reached SVR, whereas among 130 non-cirrhotic patients, $79(60.8 \%)$ reached SVR (PR 0.74; 95\% CI 0.53-1.04; $\mathrm{p}=0.081$ ) (Table 2). The relationship between SVR and liver fibrosis stage can also be observed in Figure 1. Among the monoinfected patients, the treatment duration (24 or 48 weeks) was not associated with SVR ( $\mathrm{p}=0-.754)$. This was also observed in patients co-infected with HIV ( $\mathrm{p}=0-.064)$.

Among the study population, 34 patients $(18.5 \%)$ had at least one SAE and had to interrupt treatment before completion. Early treatment interruption was observed in 20 $(20 / 114,17.5 \%)$ and $14(14 / 70,20 \%)$ patients with monoor co-infection, respectively (PR 1.14; 95\% CI 0.62-2.11; $\mathrm{p}=0.677)$. In all cases, the reason for interruption was an SAE (Table 3).

Table 2 - Distribution of patients with genotype 3 chronic hepatitis $C$ according to clinical and therapeutic characteristics as well as sustained virological response (SVR)

\begin{tabular}{|c|c|c|c|c|c|c|}
\hline \multirow{2}{*}{ Variables } & \multirow{2}{*}{ Total } & \multicolumn{2}{|c|}{ SVR } & \multirow{2}{*}{ PR } & \multirow{2}{*}{ IC 95\% (PR) } & \multirow{2}{*}{$\mathrm{p}$-value } \\
\hline & & $\mathrm{n}^{\circ}$ & $\%$ & & & \\
\hline \multicolumn{6}{|l|}{ Sex } & 0.427 \\
\hline Female & 73 & 39 & 53.4 & 0.90 & $0.69-1.17$ & \\
\hline $\mathrm{Age}^{\mathrm{a}}$ & $\ldots$ & $\ldots$ & $\ldots$ & 0.99 & $0.98-1.00$ & 0.198 \\
\hline \multicolumn{6}{|l|}{ HCV/HIV co-infection } & 0.241 \\
\hline Yes & 70 & 36 & 51.4 & 0.85 & $0.65-1.12$ & \\
\hline \multicolumn{6}{|l|}{ Metabolic syndrome } & 0.479 \\
\hline Yes & 36 & 20 & 55.6 & 0.88 & $0.63-1.24$ & \\
\hline \multicolumn{6}{|l|}{ Elevated ALT $(n=181)$} & 0.685 \\
\hline Yes & 92 & 51 & 55.4 & 0.95 & $0.74-1.22$ & \\
\hline \multicolumn{6}{|l|}{ Fibrosis ( $n=179$ ) } & 0.081 \\
\hline 4 & 49 & 22 & 44.9 & 0.74 & $0.53-1.04$ & \\
\hline \multicolumn{6}{|l|}{ Inflammatory activity $(n=151)$} & 0.675 \\
\hline 3 or 4 & 38 & 20 & 52.6 & 0.93 & $0.66-1.31$ & \\
\hline \multicolumn{6}{|l|}{ Steatosis $(n=148)$} & 0.479 \\
\hline Yes & 84 & 45 & 53.6 & 0.90 & $0.68-1.20$ & \\
\hline \multicolumn{6}{|l|}{ Prior treatment $(n=182)$} & 0.864 \\
\hline Yes & 85 & 48 & 56.5 & 0.98 & $0.76-1.26$ & \\
\hline \multicolumn{6}{|l|}{ Current treatment $(n=177)$} & 0.045 \\
\hline Peg IFN 2b & 76 & 37 & 48.7 & 0.75 & $0.58-0.99$ & \\
\hline \multicolumn{6}{|c|}{ Adequate Ribavirin dose at the beginning of treatment $(n=161)$} & 0.136 \\
\hline Yes & 144 & 84 & 58.3 & 1.65 & $0.85-3.20$ & \\
\hline \multicolumn{6}{|c|}{ Adequate Ribavirin dose at the throughout the treatment $(n=114)$} & 0.757 \\
\hline Yes & 89 & 53 & 59.6 & 1.06 & $0.72-1.57$ & \\
\hline \multicolumn{6}{|c|}{ Early treatment interruption due to severe adverse event } & 0.001 \\
\hline Yes & 34 & 8 & 23.5 & 0.36 & $0.20-0.68$ & \\
\hline
\end{tabular}

a age analyzed as a continuous variable 


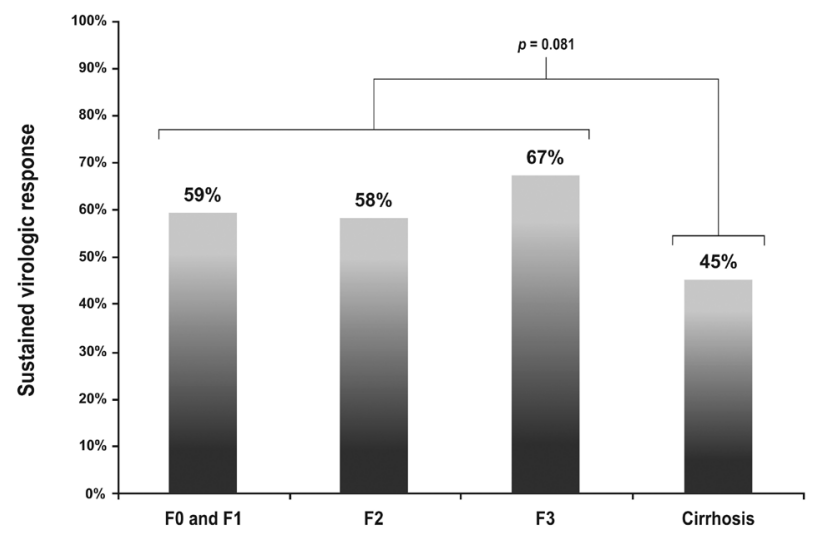

Figure 1 - Rate of sustained virologic response obtained with Peg-IFN/RBV treatment of patients with Genotype 3 Hepatitis $\mathrm{C}$ and different degrees of liver fibrosis (F0 to cirrhosis)

Bivariate analysis was used to evaluate a possible association between early treatment interruption due to SAE and the different evaluated variables. Early interruption was associated with age (PR 1.06; 95\% CI: 1.02-1.10; $\mathrm{p}<0.001$ ), and liver cirrhosis (PR 2.06; 95\% CI: 1.11-3.83; $\mathrm{p}=0.022$ ) (Table 4). The mean age of patients who interrupted their treatments before completion was 52.29 (SD 6.778) and among those who did not go through early interruptions was 47.35 (SD 9.117), ( $\mathrm{p}=0.005)$.

Among patients with liver cirrhosis, approximately $30 \%$ interrupted treatment due to SAEs, while among patients with less severe hepatic disease this rate was $15 \%(\mathrm{p}=0.022)$ (Figure 2).

\section{DISCUSSION}

In this real-life study including GEN3 CHC patients, with or without HIV co-infections, the overall rate of SVR was $57.1 \%$, with no differences between mono- $(60.5 \%)$ and co-infected patients $(51.4 \%)(\mathrm{p}=0.241)$. The use of Peg-IFN alpha $2 \mathrm{~b}$ and early treatment interruption due to SAE were negatively associated with SVR ( $\mathrm{p}=0.045$ and $\mathrm{p}=0.001$, respectively).

Among a study population of 184 patients, 34 (18.5\%) had at least one SAE and had to interrupt treatment. Such early interruptions were associated with age $(\mathrm{p}<0.001)$ and with the presence of liver cirrhosis $(\mathrm{p}=0.022)$.

The overall SVR rate observed here for patients with GEN3 corroborates the findings of other authors who used combined Peg-IFN/RBV treatment.

When giving the same CHC treatment to co-infected patients, several authors have reported higher frequencies of $\mathrm{SAE}$, as well as lower SVR rates in comparison with monoinfected patients ${ }^{14}$. However, more recently, Monje-Agudo et al. ${ }^{15}$ specifically assessing SVR in GEN3 patients found no effect of HIV presence in the attainment of SVR. Much like these previous authors, we could not find an effect of co-infection by HIV on SVR rates in GEN3 patients. It is possible that specific clinical characteristics of our population of co-infected individuals contributed to mask the effects of HIV on SVR rates.

According to criteria established by the Brazilian Ministry of Health, CHC treatment of co-infected patients is recommended for those under stable immunological condition. Therefore, it is possible that this condition, which was observed for most patients included in our study, may partially explain why SVR rates in HIV-HCV patients were similar to those observed in mono-infected individuals. This pattern may arise from the immunomodulating activity of Peg-IFN/RBV, which depends on the immunological status of patients ${ }^{16}$.

Table 3 - Frequency of serious adverse events that resulted in the early interruption of HCV treatment with Peg-IFN/RBV for monoinfected (HCV) or co-infected (HCV/HIV) patients

\begin{tabular}{|c|c|c|c|c|c|}
\hline \multirow{2}{*}{ Severe Adverse Event } & \multicolumn{2}{|c|}{ Mono-infection HCV } & \multicolumn{2}{|c|}{ Co-infection HCV/HIV } & \multirow{2}{*}{$\mathrm{p}$-value } \\
\hline & $\mathrm{N}$ & $\%$ & $\mathrm{~N}$ & $\%$ & \\
\hline Anemia & 3 & 2 & 5 & 7 & 0.145 \\
\hline Thrombocytopenia & 5 & 4 & 5 & 7 & 0.423 \\
\hline Treatment intolerance & 2 & 1 & 3 & 4 & $0.370^{*}$ \\
\hline Psychiatric complications & 2 & 1 & 2 & 2 & $0.636^{*}$ \\
\hline Cutaneous rash & 2 & 1 & 0 & 0 & $0.526^{*}$ \\
\hline Infectious complications ${ }^{a}$ & 3 & 2 & 1 & 1 & $>0.999^{*}$ \\
\hline Hepatic decompensation & 2 & 1 & 2 & 2 & $0.636^{*}$ \\
\hline Decompensation of other comorbidities ${ }^{b}$ & 2 & 1 & 2 & 2 & $0.636^{*}$ \\
\hline Any severe adverse event & 20 & 18 & 14 & 20 & 0.677 \\
\hline
\end{tabular}

* Fischer exact test. ${ }^{a}$ One case of each of the following conditions: sepsis with pulmonary focus, erysipela, pulmonary abscess, opportunistic infection. ${ }^{b}$ Two cases of cardiac decompensation, one case of thyroid decompensation, and one case of chemical dependence. 
Table 4 - Distribution of patients with genotype 3 chronic hepatitis $C$ according to clinical and therapeutic characteristics as well as early treatment interruption

\begin{tabular}{|c|c|c|c|c|c|c|}
\hline \multirow{2}{*}{ Variables } & \multirow{2}{*}{ Total } & \multicolumn{2}{|c|}{ Early interruption } & \multirow{2}{*}{ PR } & \multirow{2}{*}{$\mathrm{Cl} 95 \%(\mathrm{PR})$} & \multirow{2}{*}{ p-value } \\
\hline & & $\mathrm{n}$ & $\%$ & & & \\
\hline \multicolumn{6}{|l|}{ Sex } & 0.331 \\
\hline Female & 73 & 16 & 21.9 & 1.35 & $0.74-2.48$ & \\
\hline Age $^{a}$ & $\ldots$ & $\ldots$ & $\ldots$ & 1.06 & $1.02-1.10$ & 0.001 \\
\hline \multicolumn{6}{|l|}{ HCV/HIV co-infection } & 0.677 \\
\hline Yes & 70 & 14 & 20.0 & 1.14 & $0.62-2.11$ & \\
\hline \multicolumn{6}{|l|}{ Metabolic syndrome } & 0.054 \\
\hline Yes & 36 & 10 & 27.7 & 2.17 & $0.99-4.75$ & \\
\hline \multicolumn{6}{|l|}{ Elevated ALT $(n=181)$} & 0.395 \\
\hline Yes & 92 & 19 & 20.6 & 1.31 & $0.77-2.46$ & \\
\hline \multicolumn{6}{|l|}{ Fibrosis $(n=179)$} & 0.022 \\
\hline Grade 4 & 49 & 14 & 28.5 & 2.06 & $1.11-3.83$ & \\
\hline \multicolumn{6}{|l|}{ Inflammatory activity $(n=151)$} & 0.218 \\
\hline Grade 3 or 4 & 38 & 9 & 23.7 & 1.57 & $0.76-3.24$ & \\
\hline \multicolumn{6}{|l|}{ Steatosis $(n=148)$} & 0.379 \\
\hline Yes & 84 & 18 & 21.4 & 1.37 & $0.68-2.77$ & \\
\hline \multicolumn{6}{|l|}{ Prior treatment $(n=182)$} & 0.739 \\
\hline Yes & 85 & 15 & 17.6 & 0.90 & $0.49-1.66$ & \\
\hline \multicolumn{6}{|l|}{ Current treatment $(n=177)$} & 0.723 \\
\hline Peg IFN 2b & 76 & 12 & 15.8 & 0.89 & $0.45-1.73$ & \\
\hline \multicolumn{6}{|c|}{ Adequate Ribavirin dose at the beginning of treatment ( $n=161$ ) } & 0.470 \\
\hline Yes & 144 & 24 & 16.6 & 0.71 & $0.28-1.80$ & \\
\hline \multicolumn{6}{|c|}{ Adequate Ribavirin dose at the during treatment $(n=114)$} & 0.082 \\
\hline Yes & 89 & 12 & 13.5 & 0.48 & $0.21-1.10$ & \\
\hline
\end{tabular}

a age analyzed as a continuous variable

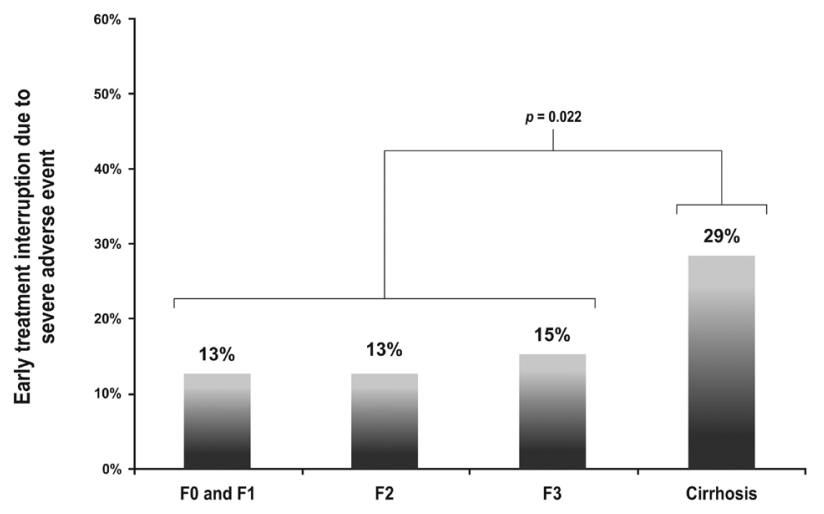

Figure 2 - Percentage of patients, with different degrees of liver fibrosis (F0 to cirrhosis), who interrupted treatment with Peg-IFN/RBV due to serious adverse events

Liver cirrhosis is considered an important indicator of poor CHC treatment outcome and low SVR rates ${ }^{9,12,15}$. However, this association was not observed in the present study, although a non-significant tendency in this direction did occur. Among 49 cirrhotic patients, 22 (44.9\%) attained SVR, whereas $60.8 \%$ of non-cirrhotic patients had SVR $(\mathrm{p}=0.081)$. We cannot exclude the possibility that the number of evaluated patients was just too small to reveal a statistically significant association.

According to our data, the use of Peg-IFN alpha 2a was associated with a higher rate of SVR when compared with the use of Peg-IFN alpha 2b, in bivariate analysis. The superior performance of Peg-IFN alpha 2a in relation to Peg-IFN alpha $2 b$ for the treatment of $\mathrm{CHC}$ constitutes a controversial theme. A few studies have indicated the existence of this difference ${ }^{17,18}$, but a recent systematic review could not establish the superiority of either Peg-IFN presentation $^{18}$.

The development of direct-action antiviral agents (DAAs) brought about a large increase in SVR rates for both mono- and co-infected patients. However, cirrhotic 
patients infected by GEN3 genotypes do not respond well to the recommended drugs ${ }^{4-6}$.

In Brazil and in different regions of the world, the association of sofosbuvir and daclatasvir is often recommended to patients infected with GEN $3^{8,19,20}$. This combination treatment usually results in SVR rates ranging from $63 \%$ to $97 \%{ }^{21,22}$. Some factors have a negative effect on the outcome. For example, the presence of liver cirrhosis, amount of time on medication, non-adhesion to treatment, resistance to NS5A inhibitors and lower SVR rates ranging from $25 \%$ to $60 \%{ }^{21-23}$.

In the present study, we observed an overall SVR frequency of $57.1 \%$, whereas, among cirrhotic patients, this rate was $45 \%$. In patients with less advanced hepatic disease, the SVR varied between $59 \%$ and $67 \%$. These results agree with others, and further support the use of Peg-IFN/RBV in patients infected with GEN3, especially those who do not have cirrhosis. It is important to note that prior use of this combination seems not to select resistant viral strains, which otherwise would pose an obstacle to patients who do not respond well to therapeutic regimens involving proteases or NS5A inhibitors ${ }^{23}$.

In the current work, 34 (18.5\%) patients had at least one SAE and had to interrupt treatment before completion. Different randomized and real-life studies have identified SAE and intolerance to Peg-IFN/RBV as the most important indicators of non-adhesion to this therapeutic regimen ${ }^{24,25}$. These authors found treatment interruption rates by SAE that were similar to ours, ranging between $8 \%$ and $15 \%{ }^{24,25}$. Interestingly, we did not observe an increase in the frequency of SAEs with HIV co-infection.

As expected, we observed a negative association between early treatment interruption by SAE and SVR. On the other hand, SAEs were positively associated with advancing age and hepatic cirrhosis. The latter has also been correlated to treatment interruption by other authors ${ }^{26,27}$. Previous work has also indicated that advancing age is associated with worse interferon treatment outcome ${ }^{28}$. The presence of comorbidities, such as depression, and the use of injectable drugs have been identified as factors that negatively affect responses to Peg-IFN/RBV ${ }^{29}$. We cannot rule out potential contributions of these or other comorbidities to the levels of the observed SVR as these factors were not analyzed in our study.

The main limitation of our study arises from intrinsic characteristics of its retrospective design. The registration bias is an important component of this limitation, because data were not collected through a rigid protocol developed for the survey. Thus, important variables that could help flush out more indicators were left out, such as alcohol consumption, BMI, IL-28B polymorphism, HCV viral load at the beginning of treatment. We must also mention that the study spanned over a period of almost five years, during which clinical protocols that guided Peg-IFN/ RBV treatment were slightly altered. Thus, RBV dose and duration of treatment underwent some modifications expected to occur in real-life studies. In any case, the guidelines of the Brazilian Health Ministry have always being followed, ensuring a good level of homogenization of the treatment received by patients.

Another limitation of retrospective studies like ours is the fact that in this type of study, it is not possible to determine how many patients with chronic genotype 3 $\mathrm{HCV}$ infection and treatment indication have been initially considered eligible for treatment, or refused treatment. We cannot exclude the possibility that the patients selected for treatment and with a higher likelihood of achieving SVR were included in our analysis.

In relation to the monitoring of adherence to treatment, it was not possible to access this information because of the retrospective nature of this study. Conversely, for evaluation of the treatment effectiveness in clinical practice, real-life studies offer the advantage of eliminating the potential bias of a change in behavior and conduct that might occur during the execution of a prospective study. Therefore, the retrospective nature of our study could somehow be advantageous because it provides a real assessment of the effectiveness of this type of therapy in Brazil.

In summary, the overall SVR rate was similar to previously published values from other real-life studies, and co-infection with HIV did not alter the odds of SVR or the frequency of SAEs. The rate of therapeutic success for these patients infected by GEN3 was fairly satisfactory. This finding indicates, that even now when better treatment options are available (or in settings where DAAs are not available $^{8}$ ), the use of Peg-IFN/RBV represents a viable course of treatment for GEN3/CHC, especially for young patients without more advanced liver disease. Patients within this profile also have a lower risk of SAEs and treatment interruption. It is also important to mention that the use of this regimen is not associated with the emergence of resistant viral strains in non-responders. Taking these characteristics into consideration, the use of Peg-IFN/RBV would be of importance in places where the supply of DAAs is limited or restricted to certain patient groups.

\section{REFERENCES}

1. Messina JP, Humphreys I, Flaxman A, Brown A, Cooke GS, Pybus $\mathrm{OG}$, et al. Global distribution and prevalence of hepatitis $\mathrm{C}$ virus genotypes. Hepatology. 2015;61:77-87. 
2. Campiotto S, Pinho JR, Carrilho FJ, Da Silva LC, Souto FJ, Spinelli V, et al. Geographic distribution of hepatitis C virus genotypes in Brazil. Braz J Med Biol Res. 2005;38:41-9.

3. Karageorgopoulos DE, Allen J, Bhagani S. Hepatitis C in human immunodeficiency virus co-infected individuals: is this still a “special population"? World J Hepatol. 2015;7:1936-52.

4. Ampuero J, Romero-Gómez M, Reddy KR. HCV genotype 3 - the new treatment challenge. Aliment Pharmacol Ther. 2014;39:686-98.

5. Zanaga LP, Miotto N, Mendes LC, Stucchi RS, Vigani AG. Treatment of hepatitis $\mathrm{C}$ virus genotype 3 infection with directacting antiviral agents. Braz J Med Biol Res. 2016;49:e5504.

6. Ampuero J, Romero-Gómez M. Hepatitis C virus: current and evolving treatments for genotypes 2 and 3. Gastroenterol Clin North Am. 2015;44:845-57.

7. Buti M, Esteban R. Hepatitis C virus genotype 3: a genotype that is not "easy-to-treat". Expert Rev Gastroenterol Hepatol. 2015;9:375-85.

8. European Association for the Study of the Liver. EASL Recommendations on Treatment of Hepatitis C 2016. J Hepatol. 2017;66:153-94.

9. Buti M, Llaneras J, Riveiro-Barciela M, Esteban R. Therapy for hepatitis $\mathrm{C}$ genotype 3: moving forward. J Viral Hepat. 2015;22:683-90.

10. Brasil. Ministério da Saúde. Manual técnico para o diagnóstico da infecção pelo HIV. $3^{\text {a }}$ ed. Brasília: Ministério da Saúde; 2016. [cited 2017 July 20]. Available from: http://www.aids. gov.br/sites/default/files/anexos/publicacao/2013/55594/ manual_tecnico_hiv_2016_final_25_07_pdf_54115.pdf

11. Brandão AB, Fuchs SC, Silva, Emer LF. Diagnóstico da hepatite C na prática médica: revisão da literatura. Rev Panam Salud Pública. 2001;9:161-8.

12. Ford ES, Giles WH, Dietz WH. Prevalence of the metabolic syndrome among US adults: findings from the third National Health and Nutrition Examination Survey. JAMA. 2002;287:356-9.

13. Hanouneh IA, Feldstein AE, Lopez R, Yerian L, Pillai A, Zein $\mathrm{CO}$, et al. Clinical significance of metabolic syndrome in the setting of chronic hepatitis $\mathrm{C}$ virus infection. Clin Gastroenterol Hepatol. 2008;6:584-9.

14. Adeyemi OM. Hepatitis C in HIV-positive patients--treatment and liver disease outcomes. J Clin Gastroenterol. 2007;41:75-87.

15. Monje-Agudo P, Castro-Iglesias A, Rivero-Juárez A, MartínezMarcos F, Ortega-González E, Real LM, et al. Impact of HIV infection on sustained virological response to treatment against hepatitis $\mathrm{C}$ virus with pegylated interferon plus ribavirin. Eur J Clin Microbiol Infect Dis. 2015;34:1929-36.

16. Feld JJ, Hoofnagle JH. Mechanism of action of interferon and ribavirin in treatment of hepatitis C. Nature. 2005;436:967-72.

17. Rumi MG, Aghemo A, Prati GM, D'Ambrosio R, Donato MF, Soffredini R, et al. Randomized study of peginterferon-alpha2a plus ribavirin vs peginterferon-alpha2b plus ribavirin in chronic hepatitis C. Gastroenterology. 2010;138:108-15.

18. Hauser G, Awad T, Thorlund K, Štimac D, Mabrouk M, Gluud C. Peginterferon alpha-2a versus peginterferon alpha-2b for chronic hepatitis C. Cochrane Database Syst Rev. 2014;CD005642.

19. Brasil. Ministério da Saúde. Protocolo clínico e diretrizes terapêuticas para hepatite $C$ e coinfecções. Brasília: Ministério da Saúde; 2015. [cited 2017 July 20]. Available from: http:// bvsms.saude.gov.br/bvs/publicacoes/protocolo_clinico_ diretrizes_hepatite_co_coinfeccoes.pdf

20. AASLD/IDSA HCV Guidance Panel. Hepatitis C guidance: AASLD-IDSA recommendations for testing, managing, and treating adults infected with hepatitis $\mathrm{C}$ virus. Hepatology. 2015;62:932-54.

21. Nelson DR, Cooper JN, Lalezari JP, Lawitz E, Pockros PJ, Gitlin N, et al. All-oral 12-week treatment with daclatasvir plus sofosbuvir in patients with hepatitis $\mathrm{C}$ virus genotype 3 infection: ALLY-3 phase III study. Hepatology. 2015;61:112735.

22. Leroy V, Angus P, Bronowicki JP, Dore GJ, Hezode C, Pianko S, et al. Daclatasvir, sofosbuvir, and ribavirin for hepatitis $\mathrm{C}$ virus genotype 3 and advanced liver disease: a randomized phase III study (ALLY-3+). Hepatology. 2016;63:1430-41.

23. Sarrazin C. The importance of resistance to direct antiviral drugs in HCV infection in clinical practice. J Hepatol. 2016;64:486504.

24. Marcellin P, Cheinquer H, Curescu M, Dusheiko GM, Ferenci P, Horban A, et al. High sustained virologic response rates in rapid virologic response patients in the large real-world PROPHESYS cohort confirm results from randomized clinical trials. Hepatolology. 2012;56:2039-50.

25. Manns MP, McHutchison JG, Gordon SC, Rustgi VK, Shiffman $\mathrm{M}$, Reindollar R, et al. Peginterferon alfa-2b plus ribavirin compared with interferon alfa-2b plus ribavirin for initial treatment of chronic hepatitis C: a randomised trial. Lancet. 2001;358:958-65.

26. Bota S, Sporea I, Sirli R, Popescu A, Neghină AM, Dănilă M, et al. Severe adverse events during antiviral therapy in hepatitis $C$ virus cirrhotic patients: a systematic review. World J Hepatol. 2013;5:120-6.

27. Wright TL. Treatment of patients with hepatitis $\mathrm{C}$ and cirrhosis. Hepatology. 2002;36 Suppl 1:S185-94.

28. Cheetham TC, Niu F, Chiang K, Yuan Y, Kalsekar A, Hechter R, et al. Factors associated with failure to achieve SVR in hepatitis C genotype 3 patients within an integrated care delivery system. J Manag Care Spec Pharm. 2015;21:641-7.

29. Strader DB, Wright T, Thomas DL, Seeff LB. Diagnosis, management, and treatment of hepatitis C. Hepatology. 2004;39:1147-71. 